(C) 2018, Elsevier. Licensed under the Creative Commons Attribution-NonCommercial-

NoDerivatives 4.0 International

http://creativecommons.org/licenses/by-nc-nd/4.0/ Accepted Manuscript

Title: Platinum catalysed aerobic selective oxidation of cinnamaldehyde to cinnamic acid

Authors: Lee J. Durndell, Costanza Cucuzzella, Christopher M.A. Parlett, Mark A. Isaacs, Karen Wilson, Adam F. Lee

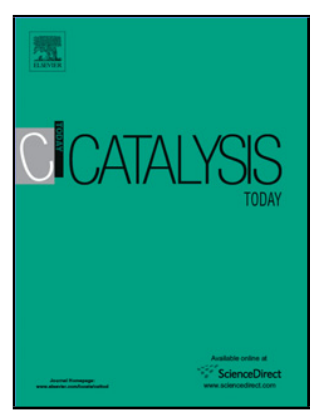

PII:

S0920-5861(18)30145-7

DOI: https://doi.org/10.1016/j.cattod.2018.02.052

Reference: CATTOD 11277

To appear in: $\quad$ Catalysis Today

Received date: $\quad 29-11-2017$

Revised date: 22-2-2018

Accepted date: $\quad$ 27-2-2018

Please cite this article as: Lee J.Durndell, Costanza Cucuzzella, Christopher M.A.Parlett, Mark A.Isaacs, Karen Wilson, Adam F.Lee, Platinum catalysed aerobic selective oxidation of cinnamaldehyde to cinnamic acid, Catalysis Today https://doi.org/10.1016/j.cattod.2018.02.052

This is a PDF file of an unedited manuscript that has been accepted for publication. As a service to our customers we are providing this early version of the manuscript. The manuscript will undergo copyediting, typesetting, and review of the resulting proof before it is published in its final form. Please note that during the production process errors may be discovered which could affect the content, and all legal disclaimers that apply to the journal pertain. 


\section{Platinum catalysed aerobic selective oxidation of cinnamaldehyde to cinnamic acid}

Lee J. Durndell, ${ }^{a}$ Costanza Cucuzzella, ${ }^{a}$ Christopher M. A. Parlett, ${ }^{a}$ Mark A. Isaacs, ${ }^{a}$ Karen Wilson ${ }^{b}$ and Adam. F. Lee b* $^{*}$

aEuropean Bioenergy Research Institute, Aston University, Birmingham, B4 7ET, UK

${ }^{\mathrm{b}}$ School of Science, RMIT University, Melbourne, Victoria 3001, Australia

\section{Graphical abstract}

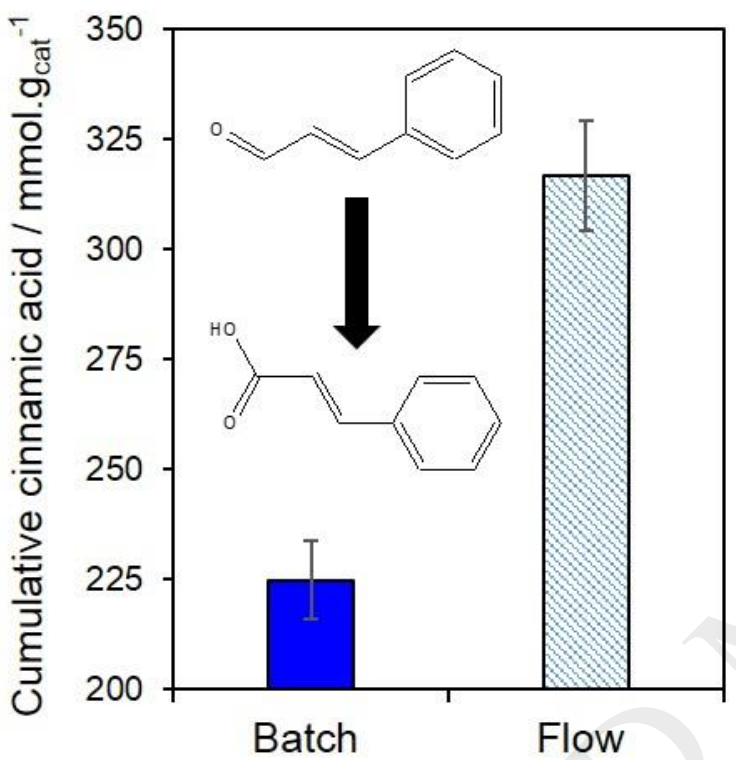

\section{Highlights}

- Silica supported Pt nanoparticles are active and selective for base-free cinnamaldehyde aerobic oxidation

- High area, mesoporous silica supports increase Pt dispersion and hence activity and cinnamic acid yield

- Surface $\mathrm{PtO}_{2}$ is the active site for selective oxidation of cinnamaldehyde $\rightarrow$ cinnamic acid

- Continuous flow operation stabilises surface $\mathrm{PtO}_{2}$ thereby significantly enhancing catalyst stability and acid yield

\footnotetext{
Abstract

Aerobic selective oxidation of allylic aldehydes offers an atom and energy efficient route to unsaturated carboxylic acids, however suitable heterogeneous catalysts offering high selectivity and productivity have to date proved elusive. Herein, we demonstrate the direct aerobic oxidation of cinnamaldehyde to cinnamic acid employing silica supported $\mathrm{Pt}$ nanoparticles under base-free, batch and continuous flow operation. Surface and bulk characterisation of four families of related Pt/silica catalysts by XRD, XPS, HRTEM, CO chemisorption and $\mathrm{N}_{2}$ porosimetry evidence surface $\mathrm{PtO}_{2}$ as the common active site for cinnamaldehyde oxidation, with a common turnover frequency of 49,000 $\pm 600 \mathrm{~h}^{-1}$; competing cinnamaldehyde hydrogenolysis is favoured over metallic Pt. High area mesoporous (SBA-15 or KIT-6) and macroporous-mesoporous SBA-15 silicas confer significant rate and cinnamic acid yield enhancements versus low area
} 
fumed silica, due to superior platinum dispersion. High oxygen partial pressures and continuous flow operation stabilise $\mathrm{PtO}_{2}$ active sites against in-situ reduction and concomitant deactivation, further enhancing cinnamic acid productivity.

Keywords: Platinum; Cinnamaldehyde; Oxidation; Porous; Silica

\section{Introduction}

The aerobic selective oxidation (selox) of aldehydes represents an environmentally benign and atom efficient molecular transformation for chemical valorisation [1], affording the production of complex $\alpha, \beta$-unsaturated acids (and their esters) under mild conditions [2]. Such acids are valuable chemical products and intermediates, for example cinnamic acid is important in the fine chemical and pharmaceutical sectors as a food [3] and perfume additive [4], as a precursor to the sweetener aspartame [5], and also finds application as an anti-fungal [6] and potential anti-malarial agent [7]. Traditionally, stoichiometric amounts of hazardous inorganic oxidants were utilised in selective alcohol and aldehyde oxidation, but this approach is considered unsustainable and hence alternative catalytic clean technologies are sought [810]. The presence of proximate $\mathrm{C}=\mathrm{C}$ and $\mathrm{C}=\mathrm{O}$ functionalities pose an especial challenge to achieving high selectivity to the unsaturated acid in such aerobic oxidations [11].

Platinum group metals (PGMs) are effective heterogeneous catalysts for aerobic selox of alcohol, aldehydes and carbohydrates, and the subject of numerous reviews [9, 12-15]. In this regard, $\alpha, \beta$-unsaturated acids are typically prepared by the cascade oxidation of their corresponding alcohols under strongly basic conditions [16-19]. Platinum nanoparticles dispersed over oxide and carbon supports are widely studied for the aerobic selox of aliphatic [20-22], allylic [23-25] and benzylic [26, 27] primary and secondary alcohols and carbohydrates [28, 29], but typically utilise pblock promoters such as Bi, Pd, Sn and Te $[19,23]$ under basic conditions. Nevertheless, the nature of the active site and role(s) of promoters and base remain poorly understood, reflecting the complex solid-liquid-gas interface and necessity for (but attendant difficulties in performing and interpreting) in-situ/operando studies on supported metal catalysts for aerobic selox [30, 31]. Recent spectroscopic and kinetic studies of cinnamyl alcohol aerobic oxidation over silica supported Pt nanoparticles identified surface $\mathrm{PtO}_{2}$ as the active site for the selective production of cinnamaldehyde [32]. Hydrogen adatoms liberated during this oxidative dehydrogenation drive in-situ reduction of surface platinum oxide, with the resulting $\mathrm{Pt}^{0}$ sites favouring styrene formation through hydrogenolysis of the $\mathrm{C}-\mathrm{C}$ bond, and production of the saturated 3-phenylpropanoic acid [33]. It is interesting to note that cationic Pt is also proposed as the active species in the aerobic oxidative dehydrogenation of shikimic acid to dehydroshikimic acid over a platinum tetrasulfophthalocyanine catalyst [34]. These observations mirror palladium analogues, wherein surface PdO adlayers [35-37] and electron deficient Pd single atoms [38] are now recognised as the catalytically active species in allylic alcohol selox.

In contrast to alcohol selox, there are scant reports of the direct aerobic oxidation of unsaturated aldehydes over PGMs, these being restricted to the cascade oxidation of 5-hydroxymethylfurfural, for which Pt catalysts again require additional inorganic base (liquid or solid [39]) and/or promoters [40, 41] to achieve significant yields of 2,5furandicarboxylic acid (2,5-FDCA). There are also few examples of heterogeneously catalysed, liquid phase aerobic oxidations in continuous flow [42-45], despite the attendant process advantages for atom economical, and scalable, organic synthesis. In the context of platinum, aerobic flow oxidation of primary and secondary alcohols to their corresponding carboxylic acids is reported over Pt nanoparticles dispersed in an amphiphilic polymer resin at high oxygen pressures $\left(40-70\right.$ bar) and temperature $\left(100-120^{\circ} \mathrm{C}\right)$, which are undesirable from the perspective of developing a 
sustainable process, and for $\mathrm{Pt} / \mathrm{Al}_{2} \mathrm{O}_{3}$ in a trickle-bed reactor for ethanol and benzyl alcohol oxidation [46] albeit minimal information was provided on product selectivity.

Herein, we report one of the first examples of Pt catalysed aerobic selox of $\alpha, \beta$-unsaturated aldehydes, under mild and base-free conditions, and highlight the influence of support architecture, Pt oxidation state, and reaction conditions on the yield of cinnamic acid from cinnamaldehyde. Significant productivity enhancements are also demonstrated for continuous flow versus batch cinnamaldehyde oxidation to cinnamic acid.

\section{Experimental}

\subsection{Catalyst synthesis}

2.1.1 SBA-15 synthesis. $10 \mathrm{~g}$ Pluronic P123 was dissolved in $75.5 \mathrm{~cm}^{3}$ water and $291.5 \mathrm{~cm}^{3}$ of $2 \mathrm{M}$ hydrochloric acid under stirring at $35{ }^{\circ} \mathrm{C} .15 .5 \mathrm{~cm}^{3}$ Tetraethylorthosilicate was subsequently added and left stirring for $20 \mathrm{~h}$. The resulting gel was aged for $24 \mathrm{~h}$ at $80{ }^{\circ} \mathrm{C}$ without agitation. The solid was filtered, washed with $1000 \mathrm{~cm}^{3}$ water, and dried at room temp before calcination at $500{ }^{\circ} \mathrm{C}$ for $6 \mathrm{~h}$ in air $\left(\operatorname{ramp~} 1{ }^{\circ} \mathrm{C} \cdot \mathrm{min}^{-1}\right)$. The resulting silica exhibited the expected ordered, hexagonal $(p 6 \mathrm{~mm})$ arrangements of monodispersed, uniform mesopores.

2.1.2 KIT-6 synthesis. 10g Pluronic F127 was dissolved in $361.6 \mathrm{~cm}^{3}$ water, $12.3 \mathrm{~cm}^{3}$ butan-1-ol and hydrochloric acid $\left(35 \%, 16.7 \mathrm{~cm}^{3}\right)$ with stirring at $35^{\circ} \mathrm{C} .15 .6 \mathrm{~cm}^{3}$ Tetramethoxysilane was added and left for $20 \mathrm{~h}$ with agitation. The resulting gel was aged for $24 \mathrm{~h}$ at $80{ }^{\circ} \mathrm{C}$ without agitation. The solid was filtered, washed with $1000 \mathrm{~cm}^{3}$ water and dried at room temperature before calcination at $500{ }^{\circ} \mathrm{C}$ for $6 \mathrm{~h}$ in air (ramp rate $1{ }^{\circ} \mathrm{C} \cdot \mathrm{min}^{-1}$ ). The resulting silica exhibited the expected gyroidal pore architecture (Ia3d symmetry) with interconnecting pore channels.

2.1.3 Polystyrene colloidal nanospheres. Polystyrene nanospheres were synthesised by the method of Vaudreuil and coworker, employing styrene (Sigma Aldrich, >99 \%) as the monomer source and potassium persulphate (Sigma Aldrich, $>99 \%$ ) as the initiator, in a 2 L Radleys Reactor Ready jacketed glass reactor at $80{ }^{\circ} \mathrm{C} .103 \mathrm{~cm}^{3}$ of styrene was washed five times with $0.1 \mathrm{M} \mathrm{NaOH}$ and deionised water to remove polymerisation inhibitors, and added to $1.275 \mathrm{~L}$ of deionised water previously degassed overnight in the reactor under 1.5 bar flowing $\mathrm{N}_{2}\left(10 \mathrm{~cm}^{3} . \mathrm{min}^{-1}\right)$. Subsequently, $0.33 \mathrm{~g}$ of potassium persulphate was dissolved in $50 \mathrm{~cm}^{3}$ deionised water at $70{ }^{\circ} \mathrm{C}$ and added to the styrene mixture to initiate polymerisation, and stirred at $300 \mathrm{rpm}$ under flowing $\mathrm{N}_{2}$ for $22 \mathrm{~h}$. The resultant solid was recovered, filtered and washed three times with deionised water, and a further three times with ethanol. The polystyrene nanospheres obtained were dried overnight at $80{ }^{\circ} \mathrm{C}$ to yield a final dry mass of approximately $70 \mathrm{~g}$.

2.1.4 Macro-mesoporous SBA-15 synthesis. Hierarchical macroporous-mesoporous SBA-15 was synthesised by a dual hard-soft templating approach. An organic mesophase was first prepared through True Liquid Crystal Templating by mixing $2 \mathrm{~g}$ Pluronic $\mathrm{P} 123$ with $2 \mathrm{~g}$ of $2 \mathrm{M} \mathrm{HCl}$ acidified water ( $\mathrm{pH}$ 2) and subsequent ultrasonication for $3 \mathrm{~h}$ at $40{ }^{\circ} \mathrm{C}$ to produce a homogeneous gel. To this, $4.08 \mathrm{~cm}^{3}$ of aqueous tetramethoxysilane (1:4 molar ratio in $\left.\mathrm{H}_{2} \mathrm{O}\right)$ was added and mixed, yielding a homogeneous liquid. $6 \mathrm{~g}$ of polystyrene colloidal nanospheres was subsequently added to this solution, and the resulting mixture heated at $40{ }^{\circ} \mathrm{C}$ in vacuo (100 mbar) overnight to obtain a viscous gel. The gel was aged for 24 $\mathrm{h}$ at room temperature to fully condense the silica framework, and then calcined at $500{ }^{\circ} \mathrm{C}$ (ramp rate $1^{\circ} \mathrm{C} \cdot \mathrm{min}^{-1}$ ) for $6 \mathrm{~h}$ in static air.

2.1.5 Platinum impregnation. Wet impregnation of $2 \mathrm{~g}$ each of mesoporous SBA-15, KIT-6 and MM-SBA-15 silicas, and a commercial fumed silica (Sigma Aldrich S5505, $200 \mathrm{~m}^{2} \cdot \mathrm{g}^{-1}$ ), was performed with $16 \mathrm{~cm}^{3}$ aqueous ammonium tetrachloroplatinate (II) solution (precursor concentrations adjusted to achieve nominal Pt loadings of 0.05-2 wt\%). The resulting slurries were stirred for $18 \mathrm{~h}$ at room temperature before heating to $50{ }^{\circ} \mathrm{C}$. After a further $5 \mathrm{~h}$ agitation, the 
remaining solids were held at $50{ }^{\circ} \mathrm{C}$ for $24 \mathrm{~h}$ to obtain dry powders, which were then calcined at $500{ }^{\circ} \mathrm{C}$ (ramp rate 1 ${ }^{\circ} \mathrm{C} \cdot \mathrm{min}^{-1}$ ) for $2 \mathrm{~h}$ in static air, prior to reduction at $400{ }^{\circ} \mathrm{C}\left(\operatorname{ramp}\right.$ rate $10{ }^{\circ} \mathrm{C} \cdot \mathrm{min}^{-1}$ ) for $2 \mathrm{~h}$ under $10 \mathrm{~cm}^{3} \cdot \mathrm{min}^{-1}$ flowing hydrogen. Reference $0.5 \mathrm{wt} \%$ Pt catalysts were also prepared by wet impregnation as described above on P25 (SigmaAldrich, $99.5 \%$ ) and Degussa $\mathrm{C} \gamma$-alumina (>99.8 \%) supports, to examine the impact of support reducibility.

\subsection{Characterisation}

Nitrogen porosimetry was undertaken on a Quantachrome Nova 2000e porosimeter using NovaWin version 11 analysis software. Samples were degassed at $120^{\circ} \mathrm{C}$ for $2 \mathrm{~h}$ prior to nitrogen physisorption. Adsorption/desorption isotherms were recorded for parent and Pt impregnated silicas, with BET surface areas calculated over the relative pressure range 0.01 0.2. Pore diameters and volumes were calculated by applying the BJH method to desorption isotherms for relative pressures $>0.35$. Wide angle XRD patterns were recorded on a Bruker D8 Advance diffractometer with a Cu $\mathrm{K}_{\alpha}(1.54 \AA$ ) source calibrated against a Si standard, between $2 \theta=20-90^{\circ}$ with a step size of $0.02^{\circ}$. The Scherrer equation was used to calculate volume-averaged Pt particle sizes from line broadening. Low angle XRD patterns were recorded for $2 \theta=$ 0.5-2.5 ${ }^{\circ}$ with a step size of $0.02^{\circ}$. XPS was performed on a Kratos Axis HSi X-ray photoelectron spectrometer fitted with a charge neutraliser and magnetic focusing lens employing $\mathrm{Al} \mathrm{K}_{\alpha}$ monochromated radiation (1486.7 eV). Spectral fitting was performed using CasaXPS version 2.3.14, with binding energies corrected to the $\mathrm{C} 1 \mathrm{~s}$ peak at $284.6 \mathrm{eV}$. Pt $4 \mathrm{f}$ XP spectra were fitted using an asymmetric lineshape. Pt nanoparticle dispersion as measured via CO pulse chemisorption on a Quantachrome ChemBET3000 system. Catalysts were outgassed at $150{ }^{\circ} \mathrm{C}$ under $20 \mathrm{~cm}^{3} . \mathrm{min}^{-1}$ flowing $\mathrm{He}$ for $1 \mathrm{~h}$, prior to $150{ }^{\circ} \mathrm{C}$ reduction under $10 \mathrm{~cm}^{3} \cdot \mathrm{min}^{-1}$ flowing hydrogen for $1 \mathrm{~h}$ and subsequent room temperature analysis. $\mathrm{CO}: \mathrm{Pt}_{\text {surface }}$ stoichiometry of 0.68 was assumed, since the formation of a fully saturated monolayer is energetically unfavourable under these measurement conditions. This reduction protocol is milder than that employed during wet impregnation, and does not induce additional particle sintering. Metal loading was determined by EDX analysis on a Carl Zeiss Evo-40 SEM operated at $25 \mathrm{Kv}$. High resolution high-angle annular dark-field STEM images were obtained on an aberration-corrected JEOL 2100-F microscope operated at $200 \mathrm{kV}$, with image analysis using ImageJ 1.41 software. Samples were dispersed in methanol and drop cast on 200-mesh carbon coated copper grids and dried under ambient conditions.

\subsection{Catalyst testing}

2.3.1 Batch oxidation. Catalysts were tested in a Radleys StarFish carousel reactor on a $10 \mathrm{~cm}^{3} \mathrm{scale} .50 \mathrm{mg}$ catalyst was added to a reaction mixture containing $8.4 \mathrm{mmol}$ cinnamaldehyde $(1.11 \mathrm{~g}), 0.1 \mathrm{~cm}^{3}$ mesitylene as an internal standard, and $10 \mathrm{~cm}^{3}$ toluene solvent preheated to $90{ }^{\circ} \mathrm{C}$ under 1 bar of bubbling $\mathrm{O}_{2}\left(5 \mathrm{~cm}^{3} \cdot \mathrm{min}^{-1}\right)$. The Pt concentration varied between 0.13 and $5.4 \mu \mathrm{mol}$ (for $0.05-2.10 \mathrm{wt} \%$ Pt loadings), corresponding to substrate:catalyst ratios ranging from 6.55 $\mathrm{x} 10^{4}$ to $1.56 \times 10^{3}$. Reactions were sampled periodically for by off-line gas chromatography using a Varian 3900GC with 8400 autosampler fitted with a CP-Sil5 CB column ( $15 \mathrm{~m}$ x $0.25 \mathrm{~mm}$ x $0.25 \mu \mathrm{m})$. High pressure (1-10 bar $\left.\mathrm{O}_{2}\right)$ oxidations were performed in a Parr $5513100 \mathrm{~cm}^{3}$ stainless steel stirred autoclave fitted with a dip-tube for the $0.52 \mathrm{wt} \% \mathrm{Pt} / \mathrm{SBA}-15$ catalyst using a substrate:catalyst ratio of $1.25 \times 10^{4}$ to ensure accurate kinetic analysis. In both reactors, control experiments showed negligible substrate conversion (for all screened substrates) in the absence of either $\mathrm{O}_{2}$ or platinum catalyst. Oxidation rates (and selectivity) were zero order with respect to catalyst mass, confirming reactions were free from bulk or in-pore mass-transport limitations. Hot filtration experiments evidenced negligible Pt leaching, confirming the heterogeneous nature of the observed reactivity. Activity and selectivity values are the mean of duplicate or triplicate reactions, with errors of $\pm 3 \%$ and mass balances $>96 \%$ in all cases. Conversion was calculated from Equation 1, where 
$\mathrm{n}_{t}$ is the number of mmol cinnamaldehyde at time $\mathrm{t}$, and $\mathrm{n}_{0}$ the initial mmol cinnamaldehyde, and selectivity calculated from Equation 2 based exclusively on the five major liquid phase products, where $\mathrm{n}_{x=i}$ is the mmol of product $i$ (cinnamic acid, 3-phenylpropan-1-ol, styrene, cinnamyl esters or cinnamyl alcohol) and $\Sigma \mathrm{n}_{x}$ denotes the total mmol of all products. Yield was calculated from Equation 3. Mass-normalised initial rates were calculated from the first hour of reaction, and Turnover Frequencies (TOFs) calculated from Equation $\mathbf{4}$ by normalising raw initial rates to the mmol surface Pt species determined from CO dispersion and XPS.

$\%$ Conversion $=\left[\left(\mathrm{n}_{0}-\mathrm{n}_{t}\right) /\left(\mathrm{n}_{0}\right)\right] \times 100$

$\%$ Selectivity $=\left[\left(\mathrm{n}_{x=i}\right) /\left(\Sigma \mathrm{n}_{x}\right)\right] \times 100$

$\%$ Yield $=[$ Conversion $\mathrm{x}$ Selectivity $) / 100$
Equation 1

Equation 2

Equation 3

$\mathrm{TOF}=$ mmol $_{\text {Cinnamaldehyde }}$ converted. $\mathrm{h}^{-1} /$ mmols surface $\mathrm{Pt}^{0 \text { or } \mathrm{x}+}$ Equation 4

2.3.2 Flow oxidation. Catalyst testing was conducted using a Uniqsis FlowSyn reactor, comprising a GAM II gas-liquid addition module and packed-bed microreactor with downstream backflow pressure regulator [47]. An integral HPLC pump delivered a liquid stream of $0.84 \mathrm{M}$ cinnamaldehyde in toluene (with mesitylene as internal standard) at flow rates between 0.1-2.0 $\mathrm{cm}^{3} \cdot \mathrm{min}^{-1}$, while $40 \mathrm{~cm}^{3}$ oxygen gas flow was delivered via an in-line Brooks mass flow controller and back pressure regulator. Liquid and gas feeds were pre-mixed before introduction to the catalyst bed via the GAM II module, which features a semi-permeable polymer coil and reactor mandrel heated to $90{ }^{\circ} \mathrm{C}$ to ensure efficient gas-liquid mixing and heating to prior to contact with the catalyst. $50 \mathrm{mg}$ of catalyst was diluted with quartz beads (Sigma Aldrich, mesh size $=-325)$ to minimise back pressure, and packed within a $10 \mathrm{~mm}$ i.d. x $100 \mathrm{~mm}$ OMNIFIT® glass column to give a total bed volume of $2.5 \mathrm{~cm}^{3}$, held within the glass reactor by quartz wool plugs. The reactor was vertically mounted and the gas-saturated liquid stream fed in an up-flow direction to minimise catalyst settling and maximise permeation through the catalyst bed. Neither fluidisation nor compaction of the catalyst bed was observed. The exit stream passed through a needle valve and backflow regulator, with excess gas vented prior to sampling for off-line GC analysis.

\section{Results and discussion}

\subsection{Catalyst characterisation}

Four families of Pt catalysts were synthesised employing amorphous, ordered mesoporous (SBA-15 and KIT-6), or hierarchical microporous-mesoporous (MM-SBA-15) silicas to elucidate the impact of support architecture on their physicochemical properties, and the subsequent selective aerobic oxidation of cinnamaldehyde. Mesoporous SBA-15 (p6mm) and KIT-6 (Ia3d) architectures were identified through indexing their characteristic low angle powder X-ray diffraction (XRD) patterns (Figure S1), however macropore incorporation disrupts extended SBA-15 ordering, preventing the collection of a corresponding (high quality) low angle XRD pattern for the MM-SBA-15 support. Calculated cell parameters and wall thicknesses for the mesoporous and hierarchical supports (Table S1) are in accordance with the literature [48-50]. Nitrogen porosimetry confirmed the expected type IV isotherms and type I hysteresis for the mesoporous and hierarchical supports (Figure S2), and corresponding high BET surface area and narrow BJH mesopore size distributions (Table S1 and Figure S2). In contrast, the commercial silica exhibited a type II isotherm, reflecting a disordered pore network, and low BET surface area. High resolution transmission electron microscopy (HRTEM) in Figure 1 shows hexagonal close-packed mesopores for SBA-15 [49], cubic close-packed 
mesopores for KIT-6 [48], and the incorporation of $300 \mathrm{~nm}$ macropores between hexagonal close-packed mesopore channels in MM-SBA-15 [50].

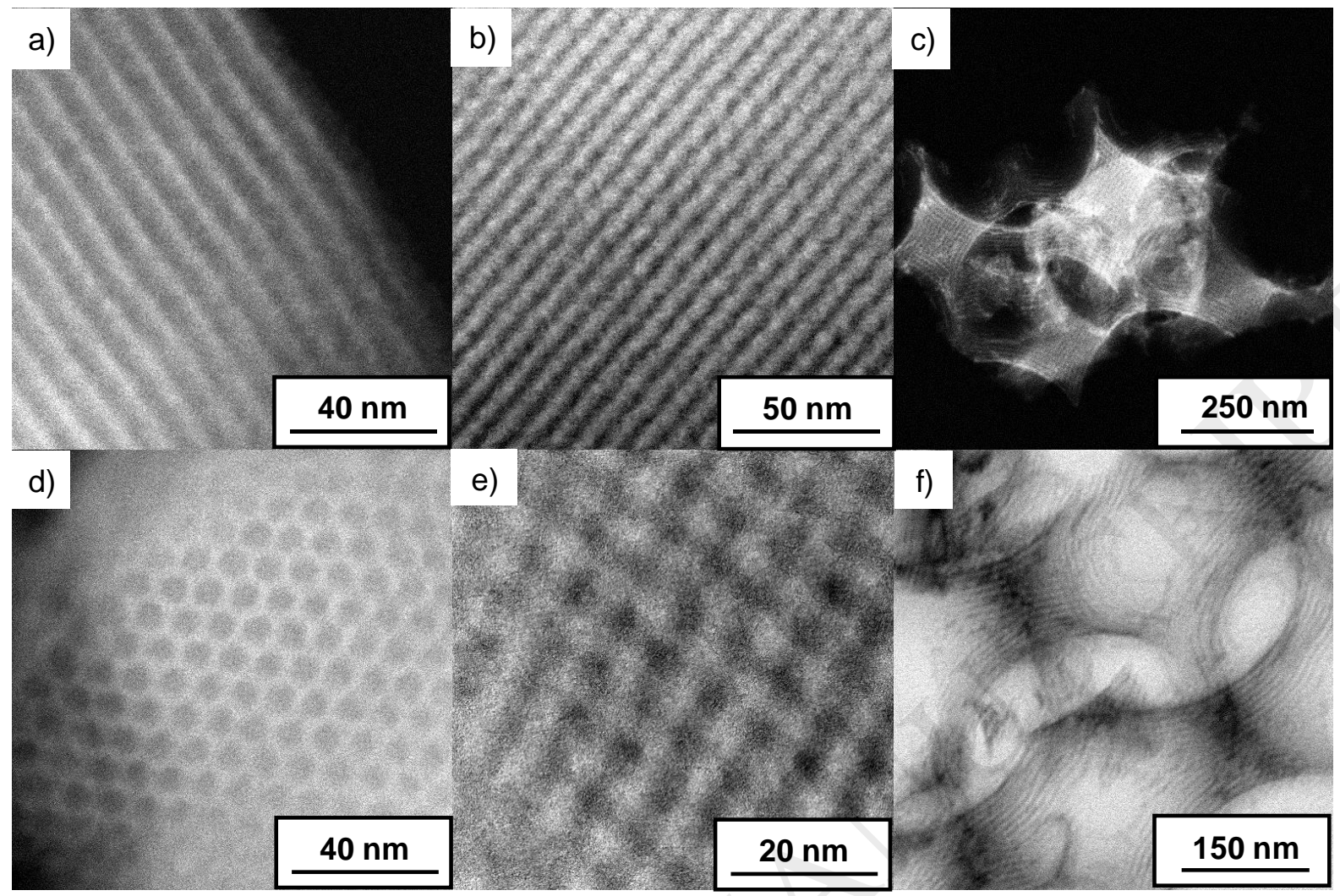

Figure 1. HRTEM dark (top) and bright (bottom) field images of (a,d) SBA-15, (b,e) KIT-6, and (c,f) MM-SBA-15 silicas.

Physicochemical characteristics of the Pt/silica analogues are summarised in Table S2, and are in excellent agreement with literature reports $[32,51,52]$. XRD, HRTEM and $\mathrm{N}_{2}$ porosimetry confirmed retention of the parent silica pore structures following platinum impregnation (Table S2, Figure S3-4), but a loss of BET surface area and pore volume proportional to Pt loading, attributed to partial pore blockage, as previously observed. The smaller magnitude of surface area decrease observed for the fumed $\mathrm{SiO}_{2}$ catalysts upon $\mathrm{Pt}$ impregnation is consistent with nanoparticle deposition primarily on the external surface. Metal dispersion (determined by $\mathrm{CO}$ chemisorption) was inversely proportional to $\mathrm{Pt}$ loading for all supports (Table S2), with particle sizes (determined by a combination of TEM, wide angle XRD (Figure S5) and CO chemisorption) proportional to the silica surface area and spanning $1.7 \mathrm{~nm}(0.07 \mathrm{wt} \% \mathrm{Pt} / \mathrm{KIT}-6)$ to $15.6 \mathrm{~nm}$ (2.10 wt\%/fumed $\mathrm{SiO}_{2}$ ). The degree of platinum surface oxidation, as measured by XPS, was directly proportional to $\mathrm{Pt}$ dispersion, as previously reported $[32,52]$ (Figure S7-8), associated with the formation of $\mathrm{PtO}_{2}$, with a $\mathrm{Pt} 4 \mathrm{f}_{7 / 2}$ binding energies of $74.5 \mathrm{eV}[32,52-54]$ over smaller nanoparticles. Platinum surface oxidation was support dependent decreasing in the order: KIT-6 > SBA-15 > MM-SBA-15 > fumed $\mathrm{SiO}_{2}$ (Table S2).

\subsection{Batch oxidation of cinnamaldehyde}

Cinnamaldehyde aerobic selox was subsequently investigated over the preceding four families of Pt/silica catalysts. Control experiments showed negligible aldehyde conversion in the absence of supported platinum and/or $\mathrm{O}_{2}$, while hot filtration tests and elemental analysis of filtrate and spent catalysts revealed negligible platinum leaching (Figure S9). 
All reactions were performed at $800 \mathrm{rpm}$, and were zero order with respect to mass-normalised catalyst activity (and selectivity), evidencing that oxidations were free from external mass-transport limitations (Figure S10 and S11). Reaction profiles are shown in Figure S12. Initial rates of cinnamaldehyde selox were inversely proportional to Pt loading for all supports (Figure 2a), with activity proportional to platinum dispersion and hence surface $\mathrm{PtO}_{2}$ concentration (Figure S13): KIT-6 > SBA-15 > MM-SBA-15 > fumed $\mathrm{SiO}_{2}$, consistent with observations for both Pd and Pt catalysed aerobic selox of cinnamyl alcohol to cinnamaldehyde [32, 55, 56]. Turnover frequencies (TOFs) for cinnamaldehyde selox normalised per surface $\mathrm{PtO}_{2}$ site were 49,000 h-1, independent of Pt loading or silica support (Figure 2b): this demonstrates that (i) $\mathrm{PtO}_{2}$ is the active site for cinnamaldehyde aerobic selox (and not Pt metal); and (ii) the superior activity of the mesoporous and hierarchical catalysts does not arise from enhanced in-pore mass transport, but is solely associated with higher Pt dispersion.

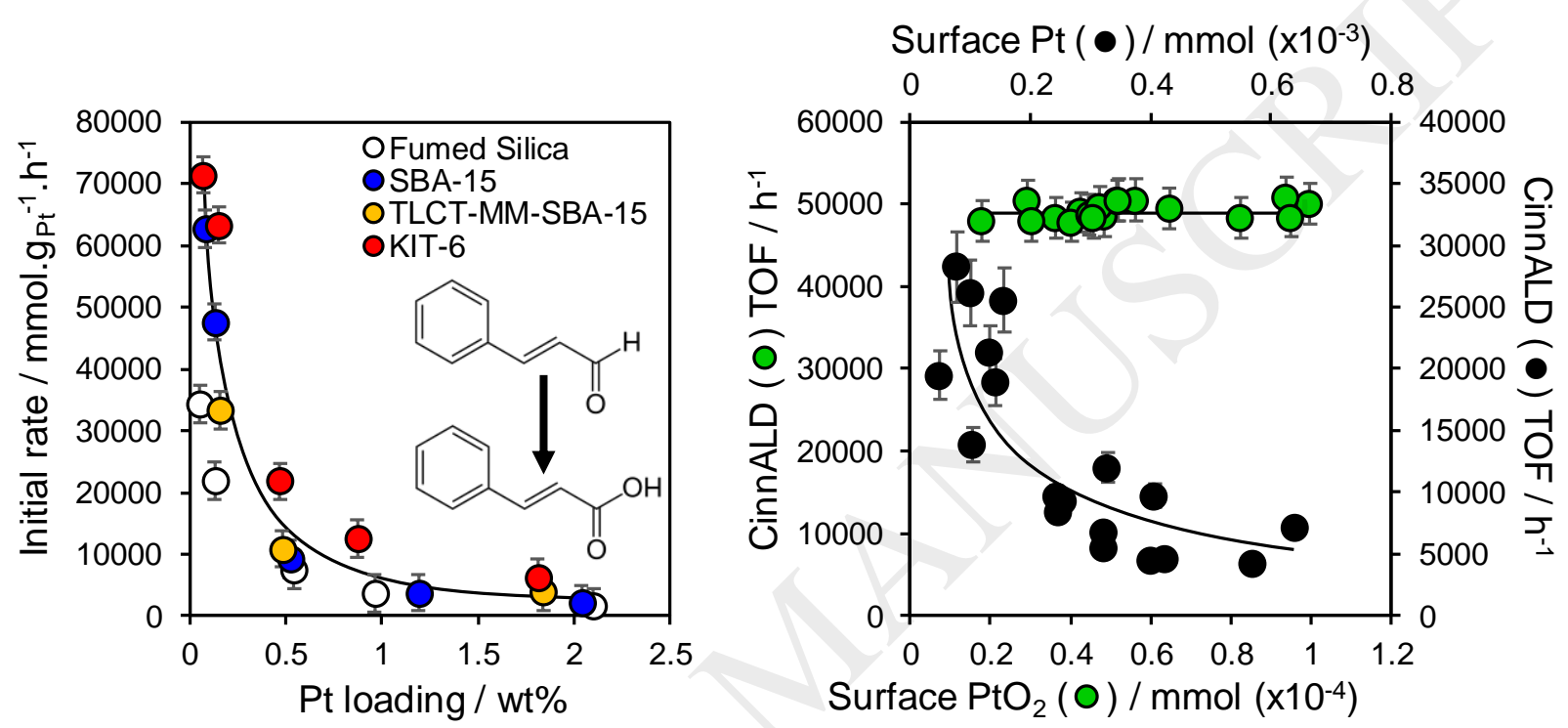

Figure 2. (left) Mass-normalised initial rates and (right) corresponding turnover frequencies for cinnamaldehyde aerobic selox over 0.05-2.1 wt\% Pt/silica catalysts. Reaction conditions: $50 \mathrm{mg}$ catalyst, $8.4 \mathrm{mmol}$ cinnamaldehyde in $10 \mathrm{~cm}^{3}$ toluene, $5 \mathrm{~cm}^{3} \cdot \mathrm{min}^{-1}$ bubbling $\mathrm{O}_{2}$ at $1 \mathrm{bar}, 90{ }^{\circ} \mathrm{C}$, and $800 \mathrm{rpm}$ stirring.

Figure 3 shows the striking performance enhancements attainable through tailoring the support porosity and surface area, which deliver a three-fold increase in mass-normalised activity and an absolute increase of $11 \%$ in cinnamic acid yield for $0.15 \mathrm{wt} \% \mathrm{Pt} /$ silicas by substituting a fumed $\mathrm{SiO}_{2}$ for a KIT-6 support. These Pt/silicas are effective catalysts for the production of $\alpha, \beta$-unsaturated acids, aliphatic and aromatic acids by aerobic oxidation (Table S3). 


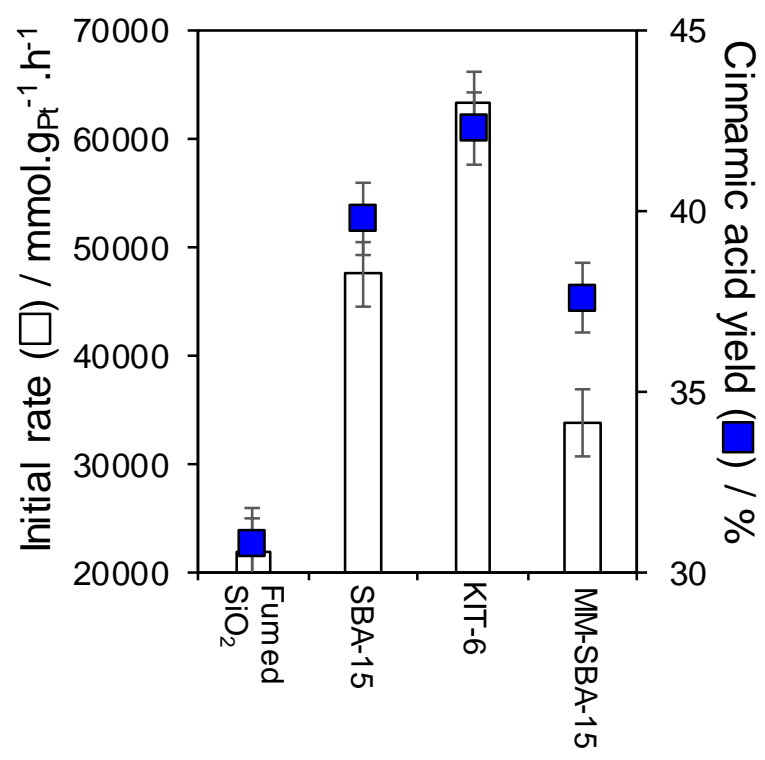

Figure 3. Comparison of initial rates and $5 \mathrm{~h}$ cinnamic acid yields for cinnamaldehyde aerobic selox over $0.15 \mathrm{wt} \%$ $\mathrm{Pt} /$ silica catalysts as a function of support architecture. Reaction conditions: $50 \mathrm{mg}$ catalyst, 8.4 mmol cinnamaldehyde in $10 \mathrm{~cm}^{3}$ toluene, $5 \mathrm{~cm}^{3} \cdot \mathrm{min}^{-1}$ bubbling $\mathrm{O}_{2}$ at $1 \mathrm{bar}, 90{ }^{\circ} \mathrm{C}$, and $800 \mathrm{rpm}$ stirring.

Figure 4 shows the product distribution as a function of surface $\mathrm{PtO}_{2}$ concentration, and confirms oxidised platinum as the active catalytic species for cinnamaldehyde aerobic selox to cinnamic acid, whereas metallic platinum favours cinnamaldehyde decarbonylation to styrene (or hydrogenation to 3-phenylpropan-1-ol); note we have been previously shown cinnamic acid does not undergo decarboxylation to styrene over Pt/silica catalysts under identical conditions [32]. Decarbonylation of reactively-formed aldehydes during aerobic selox of alcohols over Pt catalysts, and resulting site blocking by strongly-bound $\mathrm{CO}$, is reported as a major cause of catalyst deactivation in such systems [57-60]. Complementary studies by Zaera and co-workers over Pt(111) single crystal model catalysts reveal that crotonaldehyde (a simple allylic aldehyde) binds to the metal surface through the $\mathrm{C}=\mathrm{C}$ moiety, inducing extensive rehybridization of the double bond, weakening conjugation and promoting decarbonylation to adsorbed CO and gaseous propene on thermal treatment [61]. Figures 2-4 suggest that the deactivation and poor selectivity to aldehydes/acids that plagues platinum selox catalysts reflects their low nanoparticle dispersion and hence metallic surfaces. The importance of maintaining platinum in an oxidised state was further evidenced by the impact of a mild pre-reduction treatment on the performance of the $0.52 \mathrm{wt} \% \mathrm{Pt} / \mathrm{SBA}-15$ catalyst (Figure S14). Pre-reduction suppressed the initial activity and 5 h conversion by 43 $\%$ and $25 \%$ respectively for cinnamaldehyde aerobic selox, and lowered the cinnamic acid yield by $37 \%$ at the expense of increased styrene production. Furthermore, Figure S15 evidences a linear relationship between the surface $\mathrm{PtO}_{2}$ concentration and ratio of cinnamic acid:by-products. Our hypothesis that surface $\mathrm{PtO}_{2}$ is the active and selective site for cinnamaldehyde oxidation to cinnamic acid is also supported by the significant increase in aldehyde conversion (from $36 \rightarrow 86 \%)$ and acid selectivity $(67 \rightarrow 86 \%)$ observed on raising the $p \mathrm{O}_{2}$ from $1 \rightarrow 10$ bar over $0.52 \mathrm{wt} \%$ Pt/SBA-15. XPS and CHN analysis of fresh and spent $0.52 \mathrm{wt} \% \mathrm{Pt} /$ silica following $5 \mathrm{~h}$ cinnamaldehyde aerobic selox confirm that higher $p \mathrm{O}_{2}$ stabilise $\mathrm{PtO}_{2}$ and restrict site-blocking by strongly-bound organic products/residues (Figure S16). Analogous improvements in conversion and selectivity with increasing oxygen pressure are reported in the aerobic selox of glucose to glucaric acid over Pt/C [62]. Note that it is difficult to develop a quantitative relationship between the oxygen partial pressure and surface $\mathrm{PtO}_{2}$ concentration, since catalytically active surface oxides formed by platinum under high $\mathrm{O}_{2}$ 
pressures (1-5 bar) are only metastable [63]. This likely explains the non-linear relationship in Figure S16 between the increase in surface $\mathrm{PtO}_{2}$ oxide determined ex-situ by XPS post-reaction from $7.0 \rightarrow 11.4$ wt $\%$ upon raising the $p \mathrm{O}_{2}$ employed during oxidation from $1 \rightarrow 10$ bar. Accurate quantification of the $\mathrm{PtO}_{2}$ content at elevated pressures would require a liquid phase operando XAS study, which will be the subject of future investigations.
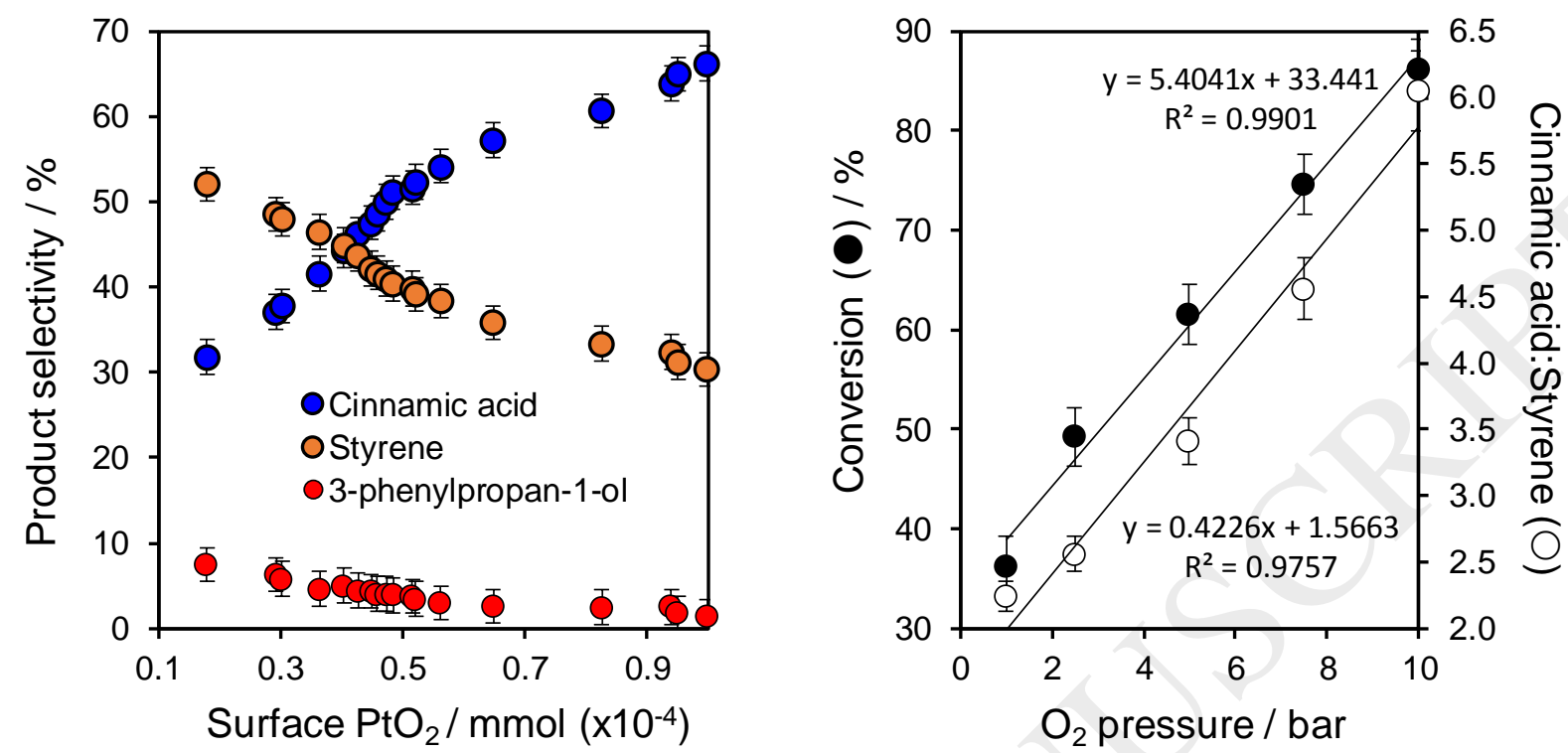

Figure 4. (left) Influence of surface $\mathrm{PtO}_{2}$ concentration on $5 \mathrm{~h}$ product selectivity for cinnamaldehyde aerobic selox over $\mathrm{Pt} /$ silicas at 1 bar $\mathrm{O}_{2}$, and (right) influence of $\mathrm{pO}_{2}$ on $5 \mathrm{~h}$ cinnamaldehyde conversion and cinnamic acid:styrene selectivity over $0.52 \mathrm{wt} \% \mathrm{Pt} / \mathrm{SBA}-15$ catalyst. Reaction conditions: $50 \mathrm{mg}$ catalyst, $16.8 \mathrm{mmol}$ cinnamaldehyde in $10 \mathrm{~cm}^{3}$ toluene, $90{ }^{\circ} \mathrm{C}$, and $800 \mathrm{rpm}$ stirring.

Having identified $\mathrm{PtO}_{2}$ as the active site in cinnamaldehyde aerobic selox, the question naturally arises as to whether higher active site densities, and hence activity, might be favoured by more reducible oxide supports which interact more strongly with platinum (and hence should enhance its dispersion and $\mathrm{PtO}_{2}$ stability). Figure 5 confirms this hypothesis, with the mass-normalised initial rates of $0.5 \mathrm{wt} \% \mathrm{Pt}$ wet-impregnated over different oxide supports decreasing in the order $\mathrm{TiO}_{2}>\mathrm{Al}_{2} \mathrm{O}_{3}>$ fumed $\mathrm{SiO}_{2}$, closely mirroring the proportion of surface $\mathrm{PtO}_{2}$ in each catalyst. 


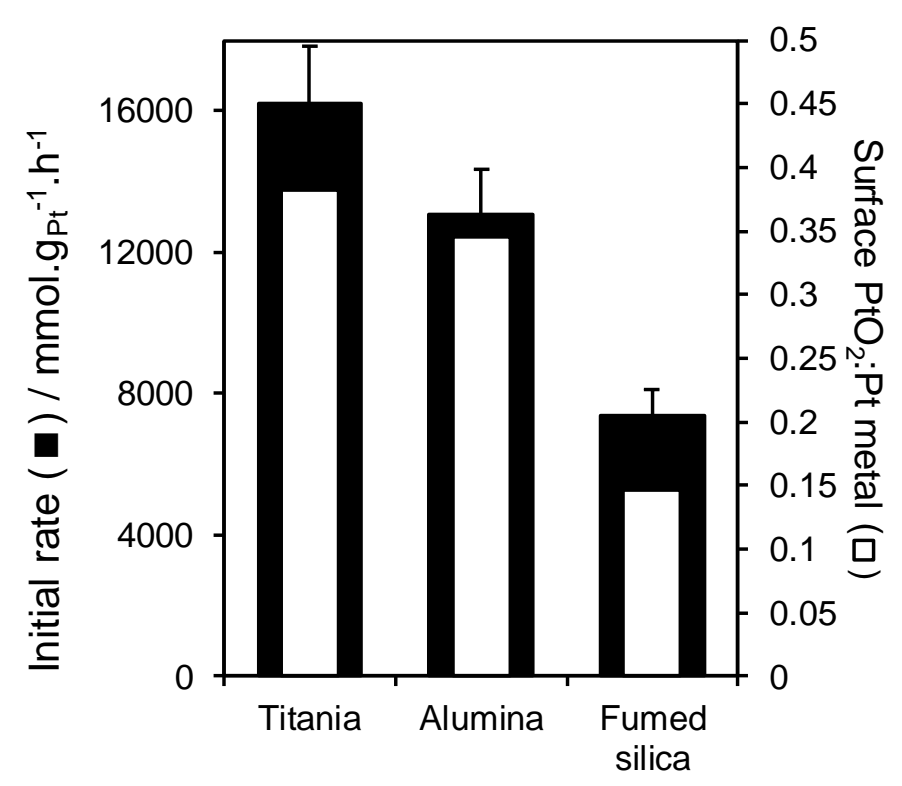

Figure 5. Comparison of mass-normalised initial rates of cinnamaldehyde aerobic selox over $0.52 \mathrm{wt} \% \mathrm{Pt}$ catalysts as a function of support, and corresponding degree of surface platinum oxidation determined by XPS of fresh catalysts. Reaction conditions: $50 \mathrm{mg}$ catalyst, $8.4 \mathrm{mmol}$ cinnamaldehyde in $10 \mathrm{ml}$ toluene, $5 \mathrm{~cm}^{3} \cdot \mathrm{min}^{-1}$ bubbling $\mathrm{O}_{2}$ at 1 bar, 90 ${ }^{\circ} \mathrm{C}$, and $800 \mathrm{rpm}$ stirring.

Cinnamaldehyde aerobic selox over shows a moderate temperature dependence (reflected by an apparent activation energy of $29 \pm 2 \mathrm{~kJ} \mathrm{~mol}^{-1}$, Figure S17), with conversion increasing from $20 \rightarrow 70 \%$ over the $0.52 \mathrm{wt} \% \mathrm{Pt} / \mathrm{SBA}-15$ catalyst with increasing reaction temperature from $20-90{ }^{\circ} \mathrm{C}$, however additional heating lowered activity possibly associated with lower oxygen solubility (Figure 6). Cinnamic acid and styrene production mirrored reactant conversion albeit with a slightly weaker temperature dependence, and indeed exhibit similar apparent activation energies of $24 \pm 2$ and $27 \pm 2$ $\mathrm{kJ} . \mathrm{mol}^{-1}$ respectively. The latter is in reasonable agreement with DFT calculations for furfural decarbonylation over a $\mathrm{Pt}_{55}$ cluster of $35 \mathrm{~kJ}^{-\mathrm{mol}^{-1}}$ [64]. In contrast, 3-phenylpropan-1-ol production was weakly temperature dependent, increasing slightly above $90^{\circ} \mathrm{C}$. High reaction temperatures therefore favoured decarbonylation $($ and $\mathrm{C}=\mathrm{C} / \mathrm{C}=\mathrm{O}$ hydrogenation), as previously observed during alcohol aerobic selox [57, 65], and which we attribute to $\mathrm{PtO}_{2}$ reduction to metallic $\mathrm{Pt}$ at elevated temperature (Figure S16) [66]. 


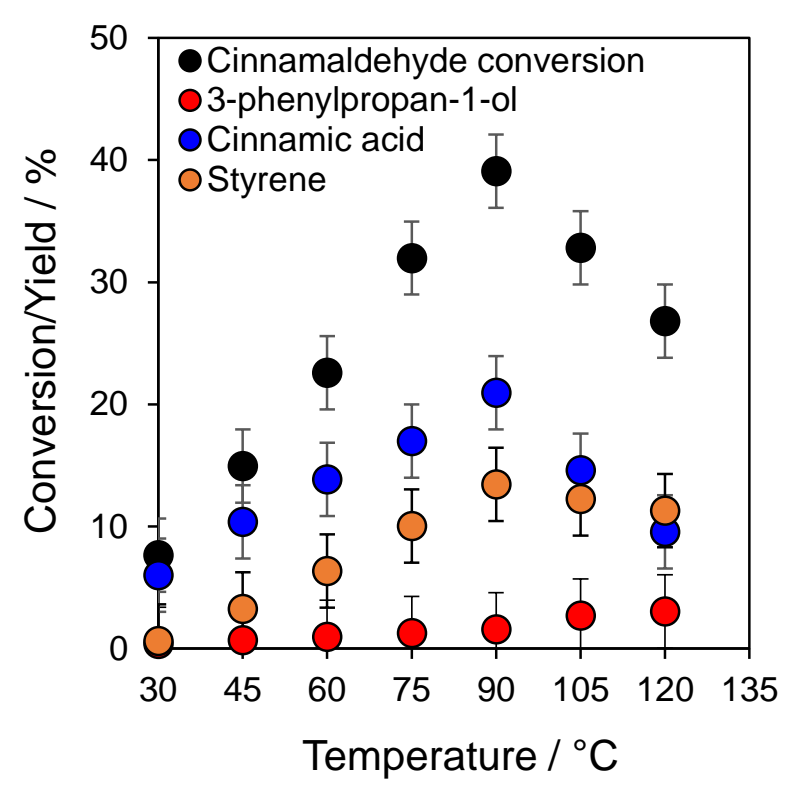

Figure 6. Influence of reaction temperature on conversion and $1 \mathrm{~h}$ product yield for cinnamaldehyde aerobic selox over 0.52 wt\% Pt/SBA-15 catalyst. Reaction conditions: $50 \mathrm{mg}$ catalyst, $8.4 \mathrm{mmol}$ cinnamaldehyde in $10 \mathrm{~cm}^{3}$ toluene, 5 $\mathrm{cm}^{3} \cdot \mathrm{min}^{-1}$ bubbling $\mathrm{O}_{2}$ at $1 \mathrm{bar}, 90{ }^{\circ} \mathrm{C}$, and $800 \mathrm{rpm}$ stirring.

\subsection{Continuous flow oxidation of cinnamaldehyde}

The potential for scale-up and impact of continuous versus batch process operation was subsequently assessed for cinnamaldehyde aerobic selox over the $0.52 \mathrm{wt} \%$ Pt/SBA-15 catalyst under the optimum reaction conditions determined in Section $3.2\left(90^{\circ} \mathrm{C}\right.$ and 10 bar $\left.\mathrm{O}_{2}\right)$. Cinnamaldehyde conversion (Figure S18) and product selectivity (Figure 7a) were first determined as a function of residence time $(\tau)$. Negligible cinnamaldehyde conversion was observed for $\tau<5$ min, with longer residence times resulting in a monotonic increase in activity, with single pass conversions reaching a plateau of $60 \%$ for $\tau>25$ min, likely due to limited oxygen availability under these conditions. Cinnamic acid production displayed a volcano dependence on residence time, reaching a maximum of $84 \%$ for $\tau=17$ min. In contrast, 3 phenylpropan-1-ol production exhibited a monotonic decrease with residence time, concomitant with a monotonic increase with styrene production, suggesting these undesired by-products are formed by competing pathways that share a common active site (which the preceding batch oxidations indicate is metallic surface Pt). The fall in cinnamic acid selectivity at the expense of styrene observed at long residence times is attributed oxygen starvation and consequent insitu reduction of surface $\mathrm{PtO}_{2}$, which Figure 4a shows is the active site for cinnamaldehyde oxidation. Catalyst stability was subsequently evaluated for $\tau=17 \mathrm{~min}$, the optimum residence time for cinnamic acid production, as a function of time-on-stream (Figure S19 and S20). Negligible deactivation was observed over $7 \mathrm{~h}$ continuous flow operation, in contrast with a batch reaction under comparable conditions in which $60 \%$ of the initial activity was lost over the same period, consistent with Figure S16 which shows greater carbon deposition and in-situ reduction of $\mathrm{PtO}_{2}$ in batch; XRD confirmed deactivation in batch was not due to particle sintering (Figure S21). High selectivity to cinnamic acid (84 \%) was also maintained in continuous flow, whereas deactivation on-stream in batch was accompanied by a slow, but continuous switchover from cinnamic acid to styrene production. Cumulative $7 \mathrm{~h}$ cinnamic acid production in batch and continuous flow is compared in Figure 7b, revealing a $37 \%$ increase in cinnamaldehyde $\rightarrow$ cinnamic acid is attainable by flow operation. 

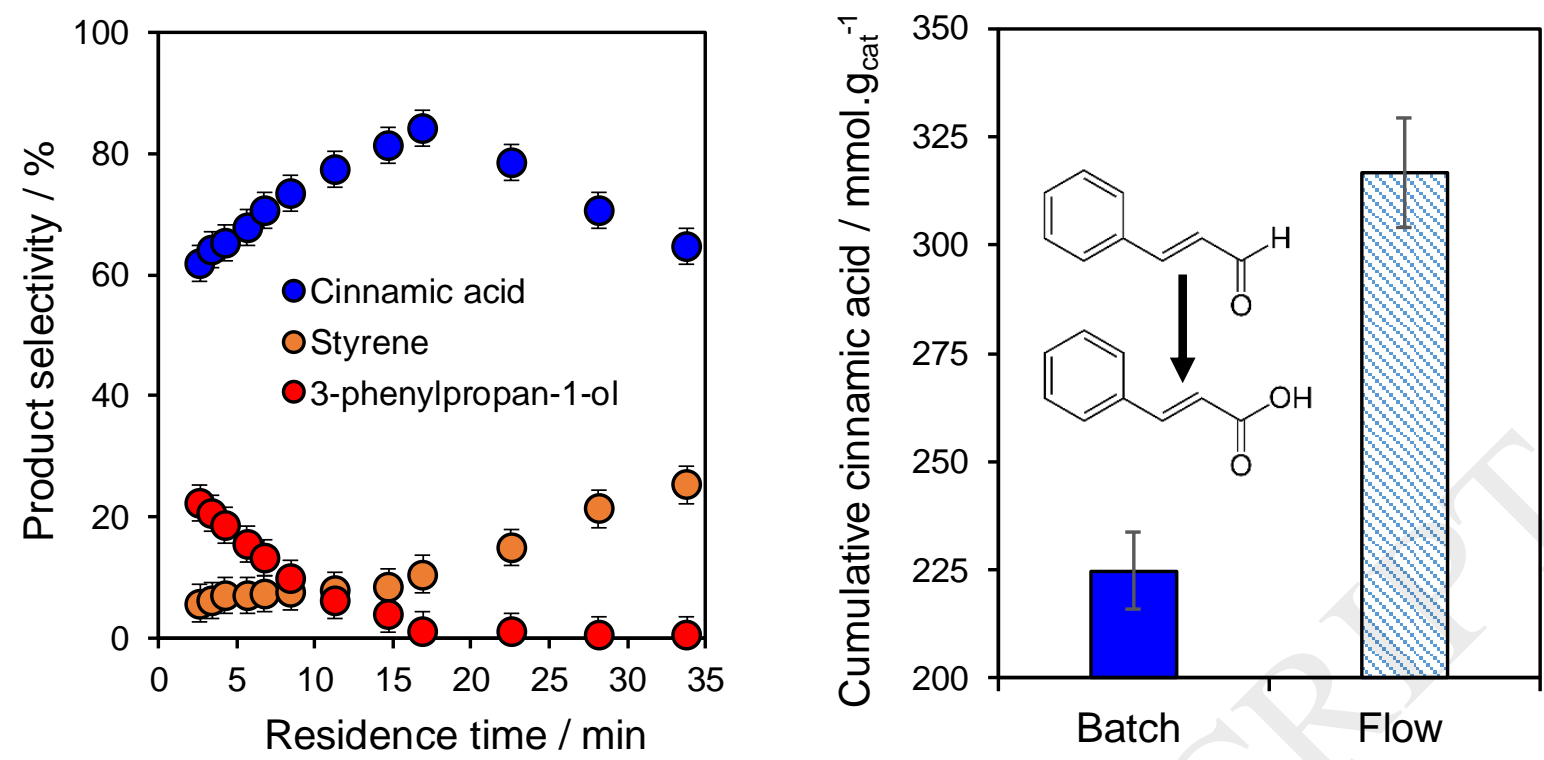

Figure 7. (left) Influence of residence time on selectivity for cinnamaldehyde aerobic selox over $0.52 \mathrm{wt} \% \mathrm{Pt} / \mathrm{SBA}-15$ in continuous flow, and (right) cumulative $7 \mathrm{~h}$ cinnamic acid yield for cinnamaldehyde aerobic selox over $0.52 \mathrm{wt} \%$ Pt/SBA-15 in batch versus continuous flow. Reaction conditions: $50 \mathrm{mg}$ catalyst, $16.8 \mathrm{mmol}$ cinnamaldehyde in $10 \mathrm{~cm}^{3}$ toluene (batch)/0.84 M (flow), 10 bar $\mathrm{O}_{2}$ (static batch, $40 \mathrm{~cm}^{3} / \mathrm{min}^{-1}$ flow), $90{ }^{\circ} \mathrm{C}, 800 \mathrm{rpm}$ stirring $(\mathrm{batch}) / 0.2 \mathrm{~cm}^{3} . \mathrm{min}^{-1}$ liquid feed (flow).

\section{Conclusions}

The influence of support architecture and process conditions on the heterogeneously catalysed liquid phase selective aerobic oxidation of cinnamaldehyde to cinnamic acid was investigated over silica supported Pt nanoparticles. In all cases, activity was directly proportional to nanoparticle dispersion and the degree of platinum oxidation. Surface $\mathrm{PtO}_{2}$ is identified as the active site responsible for cinnamic acid production, with in-situ reduction promoting cinnamaldehyde decarbonylation to styrene (and a minor hydrogenation pathway to 3-phenylpropan-1-ol) over metallic Pt; increasing the oxygen partial pressure from $1 \rightarrow 10$ bar suppresses the later undesirable side-reactions and enhances cinnamic acid productivity ( $80 \%$ selectivity and $74 \%$ yield after $5 \mathrm{~h}$ at $90{ }^{\circ} \mathrm{C}$ ). Mesoporous, high area silica supports significantly increase the concentration of active and selective surface $\mathrm{PtO}_{2}$ catalytic species, and hence cinnamic acid yield, relative to commercial fumed silica, offering a simple approach to precious metal thrifting [67]. Pt/SBA-15 is also active and selective for production of aliphatic and aromatic acids from their corresponding aldehydes. Continuous flow operation improves catalyst stability, completely suppressing on-stream deactivation observed in batch, and thereby maintaining a high $\mathrm{PtO}_{2}$ concentration (and hence selectivity to the $\alpha, \beta$-unsaturated acid of $84 \%$ ), resulting in a $37 \%$ increase in net cinnamic acid productivity over $7 \mathrm{~h}$ reaction.

\section{Declarations of interest: none}

\section{Acknowledgements}

Funding: This work was supported by the EPSRC (EP/G007594/4, EP/K014749/1 and EP/K014676/1). We thank Professor Richard Palmer and Birmingham University for access to TEM facilities. 


\section{References}

[1] J.R. McNesby, C.A. Heller, Oxidation of Liquid Aldehydes by Molecular Oxygen, Chemical Reviews, 54 (1954) 325-346.

[2] B.S. Bal, W.E. Childers, H.W. Pinnick, Oxidation of $\alpha, \beta$-un saturated aldehydes, Tetrahedron, 37 (1981) 2091-2096.

[3] D.R.A. Muhammad, D. Praseptiangga, D. Van de Walle, K. Dewettinck, Interaction between natural antioxidants derived from cinnamon and cocoa in binary and complex mixtures, Food Chemistry, 231 (2017) 356-364.

[4] D. Belsito, D. Bickers, M. Bruze, P. Calow, H. Greim, J. Hanifin, A. Rogers, J. Saurat, I. Sipes, H. Tagami, A toxicologic and dermatologic assessment of related esters and alcohols of cinnamic acid and cinnamyl alcohol when used as fragrance ingredients, Food and Chemical Toxicology, 45 (2007) S1.

[5] C.T. Evans, C. Choma, W. Peterson, M. Misawa, Bioconversion of trans-cinnamic acid to L-phenylalanine in an immobilized whole cell reactor, Biotechnology and bioengineering, 30 (1987) 1067-1072.

[6] T.C. Lima, A.R. Ferreira, D.F. Silva, E.O. Lima, D.P. de Sousa, Antifungal activity of cinnamic acid and benzoic acid esters against Candida albicans strains, Natural Product Research, (2017) 1-4.

[7] V. Gayam, S. Ravi, Cinnamoylated chloroquine analogues: A new structural class of antimalarial agents, European Journal of Medicinal Chemistry, 135 (2017) 382-391.

[8] G.-J.t. Brink, I.W.C.E. Arends, R.A. Sheldon, Green, Catalytic Oxidation of Alcohols in Water, Science, 287 (2000) 1636-1639.

[9] T. Mallat, A. Baiker, Oxidation of Alcohols with Molecular Oxygen on Solid Catalysts, Chemical Reviews, 104 (2004) 3037-3058.

[10] C.P. Vinod, K. Wilson, A.F. Lee, Recent advances in the heterogeneously catalysed aerobic selective oxidation of alcohols, Journal of Chemical Technology \& Biotechnology, 86 (2011) 161-171.

[11] Y. Wang, S. De, N. Yan, Rational control of nano-scale metal-catalysts for biomass conversion, Chemical Communications, 52 (2016) 6210-6224.

[12] M. Besson, P. Gallezot, Selective oxidation of alcohols and aldehydes on metal catalysts, Catalysis Today, 57 (2000) 127-141.

[13] J. Muzart, Palladium-catalysed oxidation of primary and secondary alcohols, Tetrahedron, 59 (2003) 5789-5816.

[14] R. Anderson, K. Griffin, P. Johnston, P.L. Alsters, Selective oxidation of alcohols to carbonyl compounds and carboxylic acids with platinum group metal catalysts, Advanced Synthesis \& Catalysis, 345 (2003) 517 523.

[15] M.E. Ali, M.M. Rahman, S.M. Sarkar, S.B.A. Hamid, Heterogeneous Metal Catalysts for Oxidation Reactions, Journal of Nanomaterials, 2014 (2014) 23.

[16] M. Besson, G. Flèche, P. Fuertes, P. Gallezot, F. Lahmer, Oxidation of glucose and gluconate on Pt, Pt Bi, and Pt Au catalysts, Recueil des Travaux Chimiques des Pays-Bas, 115 (1996) 217-221.

[17] P. Korovchenko, C. Donze, P. Gallezot, M. Besson, Oxidation of primary alcohols with air on carbonsupported platinum catalysts for the synthesis of aldehydes or acids, Catalysis Today, 121 (2007) 13-21.

[18] B. Karimi, M. Khorasani, H. Vali, C. Vargas, R. Luque, Palladium nanoparticles supported in the nanospaces of imidazolium-based bifunctional PMOs: The role of plugs in selectivity changeover in aerobic oxidation of alcohols, ACS Catalysis, 5 (2015) 4189-4200.

[19] M.S. Ahmed, D.S. Mannel, T.W. Root, S.S. Stahl, Aerobic Oxidation of Diverse Primary Alcohols to Carboxylic Acids with a Heterogeneous $\mathrm{Pd}-\mathrm{Bi}-\mathrm{Te} / \mathrm{C}$ (PBT/C) Catalyst, Organic Process Research \& Development, 21 (2017) 1388-1393.

[20] R. Garcia, M. Besson, P. Gallezot, CHEMOSELECTIVE CATALYTIC-OXIDATION OF GLYCEROL WITH AIR ON PLATINUM METALS, Appl. Catal. A-Gen., 127 (1995) 165-176.

[21] S. Carrettin, P. McMorn, P. Johnston, K. Griffin, C.J. Kiely, G.J. Hutchings, Oxidation of glycerol using supported Pt, Pd and Au catalysts, Phys. Chem. Chem. Phys., 5 (2003) 1329-1336.

[22] Y. Kwon, T.J.P. Hersbach, M.T.M. Koper, Electro-Oxidation of Glycerol on Platinum Modified by Adatoms: Activity and Selectivity Effects, Top. Catal., 57 (2014) 1272-1276. 
[23] T. Mallat, Z. Bodnar, P. Hug, A. Baiker, Selective Oxidation of Cinnamyl Alcohol to Cinnamaldehyde with Air over Bi-Pt/Alumina Catalysts, Journal of Catalysis, 153 (1995) 131-143.

[24] A.F. Lee, J.J. Gee, H.J. Theyers, Aspects of allylic alcohol oxidation - a bimetallic heterogeneous selective oxidation catalyst, Green Chem., 2 (2000) 279-282.

[25] Y. Kon, Y. Usui, K. Sato, Oxidation of allylic alcohols to alpha,beta-unsaturated carbonyl compounds with aqueous hydrogen peroxide under organic solvent-free conditions, Chemical Communications, (2007) 43994400.

[26] C. Mondelli, J.-D. Grunwaldt, D. Ferri, A. Baiker, Role of Bi promotion and solvent in platinum-catalyzed alcohol oxidation probed by in situ X-ray absorption and ATR-IR spectroscopy, Phys. Chem. Chem. Phys., 12 (2010) 5307-5316.

[27] T. Osako, K. Torii, Y. Uozumi, Aerobic flow oxidation of alcohols in water catalyzed by platinum nanoparticles dispersed in an amphiphilic polymer, RSC Advances, 5 (2015) 2647-2654.

[28] K. Heyns, H. Paulsen, Selective Catalytic Oxidation of Carbohydrates, Employing Platinum Catalysts, in: M.L. Wolfrom, R.S. Tipson (Eds.) Advances in Carbohydrate Chemistry, Academic Press1963, pp. 169-221.

[29] J.H.J. Kluytmans, A.P. Markusse, B.F.M. Kuster, G.B. Marin, J.C. Schouten, Engineering aspects of the aqueous noble metal catalysed alcohol oxidation, Catalysis Today, 57 (2000) 143-155.

[30] A.F. Lee, Mechanistic Studies of Alcohol Selective Oxidation, Heterogeneous Catalysts for Clean Technology, Wiley-VCH Verlag GmbH \& Co. KGaA2013, pp. 11-38.

[31] D. Ferri, A. Baiker, Advances in Infrared Spectroscopy of Catalytic Solid-Liquid Interfaces: The Case of Selective Alcohol Oxidation, Top. Catal., 52 (2009) 1323-1333.

[32] L.J. Durndell, C.M. Parlett, N.S. Hondow, K. Wilson, A.F. Lee, Tunable Pt nanocatalysts for the aerobic selox of cinnamyl alcohol, Nanoscale, 5 (2013) 5412-5419.

[33] K. Kon, S.H. Siddiki, K.-i. Shimizu, Size-and support-dependent Pt nanocluster catalysis for oxidant-free dehydrogenation of alcohols, Journal of catalysis, 304 (2013) 63-71.

[34] M. Nicastro, L. Tonucci, N. d'Alessandro, M. Bressan, L.K. Dragani, A. Morvillo, Platinum tetrasulfophthalocyanine as selective catalyst for the aerobic oxidation of shikimic acid, Inorganic Chemistry Communications, 10 (2007) 1304-1306.

[35] A.F. Lee, K. Wilson, Structure-reactivity correlations in the selective aerobic oxidation of cinnamyl alcohol: in situ XAFS, Green Chem., 6 (2004) 37-42.

[36] A.F. Lee, C.V. Ellis, J.N. Naughton, M.A. Newton, C.M.A. Parlett, K. Wilson, Reaction-Driven Surface Restructuring and Selectivity Control in Allylic Alcohol Catalytic Aerobic Oxidation over Pd, Journal of the American Chemical Society, 133 (2011) 5724-5727.

[37] A.F. Lee, J.N. Naughton, Z. Liu, K. Wilson, High-Pressure XPS of Crotyl Alcohol Selective Oxidation over Metallic and Oxidized Pd(111), ACS Catalysis, 2 (2012) 2235-2241.

[38] S.F.J. Hackett, R.M. Brydson, M.H. Gass, I. Harvey, A.D. Newman, K. Wilson, A.F. Lee, High-Activity, Single-Site Mesoporous Pd/Al2O3 Catalysts for Selective Aerobic Oxidation of Allylic Alcohols, Angewandte Chemie International Edition, 46 (2007) 8593-8596.

[39] X. Han, L. Geng, Y. Guo, R. Jia, X. Liu, Y. Zhang, Y. Wang, Base-free aerobic oxidation of 5hydroxymethylfurfural to 2,5-furandicarboxylic acid over a Pt/C-O-Mg catalyst, Green Chem., 18 (2016) 1597-1604.

[40] H. Ait Rass, N. Essayem, M. Besson, Selective aqueous phase oxidation of 5-hydroxymethylfurfural to 2,5-furandicarboxylic acid over Pt/C catalysts: influence of the base and effect of bismuth promotion, Green Chem., 15 (2013) 2240-2251.

[41] H. Ait Rass, N. Essayem, M. Besson, Selective Aerobic Oxidation of 5-HMF into 2,5-Furandicarboxylic Acid with Pt Catalysts Supported on TiO2- and ZrO2-Based Supports, ChemSusChem, 8 (2015) 1206-1217.

[42] H.P.L. Gemoets, Y. Su, M. Shang, V. Hessel, R. Luque, T. Noel, Liquid phase oxidation chemistry in continuous-flow microreactors, Chemical Society Reviews, 45 (2016) 83-117.

[43] B. Gutmann, U. Weigl, D.P. Cox, C.O. Kappe, Batch- and Continuous-Flow Aerobic Oxidation of 14Hydroxy Opioids to 1,3-Oxazolidines-A Concise Synthesis of Noroxymorphone, Chemistry - A European Journal, 22 (2016) 10393-10398. 
[44] D.S. Mannel, S.S. Stahl, T.W. Root, Continuous Flow Aerobic Alcohol Oxidation Reactions Using a Heterogeneous $\mathrm{Ru}(\mathrm{OH}) \times$ /Al2O3 Catalyst, Organic Process Research \& Development, 18 (2014) 1503-1508.

[45] A. Gavriilidis, A. Constantinou, K. Hellgardt, K.K. Hii, G.J. Hutchings, G.L. Brett, S. Kuhn, S.P. Marsden, Aerobic oxidations in flow: opportunities for the fine chemicals and pharmaceuticals industries, Reaction Chemistry \& Engineering, 1 (2016) 595-612.

[46] A. Muzen, M.S. Fraguío, M.C. Cassanello, M.A. Ayude, P.M. Haure, O.M. Martínez, Clean Oxidation of Alcohols in a Trickle-Bed Reactor with Liquid Flow Modulation, Industrial \& Engineering Chemistry Research, 44 (2005) 5275-5284.

[47] L.J. Durndell, K. Wilson, A.F. Lee, Platinum-catalysed cinnamaldehyde hydrogenation in continuous flow, RSC Advances, 5 (2015) 80022-80026.

[48] T.-W. Kim, F. Kleitz, B. Paul, R. Ryoo, MCM-48-like large mesoporous silicas with tailored pore structure: facile synthesis domain in a ternary triblock copolymer- butanol- water system, Journal of the American Chemical Society, 127 (2005) 7601-7610.

[49] D. Zhao, J. Feng, Q. Huo, N. Melosh, G.H. Fredrickson, B.F. Chmelka, G.D. Stucky, Triblock copolymer syntheses of mesoporous silica with periodic 50 to 300 angstrom pores, science, 279 (1998) 548-552.

[50] J. Dhainaut, J.-P. Dacquin, A.F. Lee, K. Wilson, Hierarchical macroporous-mesoporous SBA-15 sulfonic acid catalysts for biodiesel synthesis, Green Chem., 12 (2010) 296-303.

[51] Christopher M.A. Parlett, Mark A. Isaacs, Simon K. Beaumont, Laura M. Bingham, Nicole S. Hondow, K. Wilson, Adam F. Lee, Spatially orthogonal chemical functionalization of a hierarchical pore network for catalytic cascade reactions, Nature Materials, 15 (2015) 178.

[52] L.J. Durndell, C.M. Parlett, N.S. Hondow, M.A. Isaacs, K. Wilson, A.F. Lee, Selectivity control in Ptcatalyzed cinnamaldehyde hydrogenation, Scientific reports, 5 (2015).

[53] S. Cameron, D. Dwyer, Surface core level shifts in Pt3Ti (111), Surface Science Letters, 176 (1986) L857L862.

[54] G. Johansson, J. Hedman, A. Berndtsson, M. Klasson, R. Nilsson, Calibration of electron spectra, Journal of Electron Spectroscopy and Related Phenomena, 2 (1973) 295-317.

[55] C.M. Parlett, D.W. Bruce, N.S. Hondow, A.F. Lee, K. Wilson, Support-enhanced selective aerobic alcohol oxidation over Pd/mesoporous silicas, ACS Catalysis, 1 (2011) 636-640.

[56] C.M. Parlett, P. Keshwalla, S.G. Wainwright, D.W. Bruce, N.S. Hondow, K. Wilson, A.F. Lee, Hierarchically ordered nanoporous Pd/SBA-15 catalyst for the aerobic selective oxidation of sterically challenging allylic alcohols, ACS Catalysis, 3 (2013) 2122-2129.

[57] M.S. Ide, D.D. Falcone, R.J. Davis, On the deactivation of supported platinum catalysts for selective oxidation of alcohols, Journal of Catalysis, 311 (2014) 295-305.

[58] M. Caravati, J.-D. Grunwaldt, A. Baiker, Comparative in situ XAS investigations during aerobic oxidation of alcohols over ruthenium, platinum and palladium catalysts in supercritical CO 2, Catalysis Today, 126 (2007) 27-36.

[59] A.-B. Crozon, M. Besson, P. Gallezot, Oxidation of 9-decen-1-ol (rosalva) by air in aqueous media on platinum catalysts, New Journal of Chemistry, 22 (1998) 269-273.

[60] J. Beziat, M. Besson, P. Gallezot, Liquid phase oxidation of cyclohexanol to adipic acid with molecular oxygen on metal catalysts, Applied Catalysis A: General, 135 (1996) L7-L11.

[61] J.C. de Jesús, F. Zaera, Adsorption and thermal chemistry of acrolein and crotonaldehyde on Pt (111) surfaces, Surface science, 430 (1999) 99-115.

[62] J. Lee, B. Saha, D.G. Vlachos, Pt catalysts for efficient aerobic oxidation of glucose to glucaric acid in water, Green Chem., 18 (2016) 3815-3822.

[63] M.A. van Spronsen, J.W.M. Frenken, I.M.N. Groot, Observing the oxidation of platinum, Nature Communications, 8 (2017) 429.

[64] Q.-X. Cai, J.-G. Wang, Y.-G. Wang, D. Mei, Mechanistic insights into the structure-dependent selectivity of catalytic furfural conversion on platinum catalysts, AIChE Journal, 61 (2015) 3812-3824.

[65] C. Keresszegi, T. Mallat, J.-D. Grunwaldt, A. Baiker, A simple discrimination of the promoter effect in alcohol oxidation and dehydrogenation over platinum and palladium, Journal of Catalysis, 225 (2004) 138146. 
[66] L.K. Ono, B. Yuan, H. Heinrich, B.R. Cuenya, Formation and Thermal Stability of Platinum Oxides on SizeSelected Platinum Nanoparticles: Support Effects, The Journal of Physical Chemistry C, 114 (2010) 2211922133.

[67] M.B. Mooiman, K.C. Sole, N. Dinham, The Precious Metals Industry, Metal Sustainability, John Wiley \& Sons, Ltd2016, pp. 361-396. 